\title{
New Opportunities, Old Friends, and Leadership
}

\author{
Michael T. Miller, Editor
}

\section{As this issue of volume 8 of The Journal of College Orientation and Transition is} finalized, I am amazed at the wonderful people who have made this journal one of the most innovative and fastest rising in the field of higher education. Much of the credit, as well as my personal gratitude, go to Bonita C. Jacobs, Vice President for Student Services at the University of North Texas and the key editor of the Journal who has brought it to such prominence. Dr. Jacobs foresight and vision for the journal have been embraced by NODA, the professional community of orientation leaders, and the academic community. I also owe her, and the NODA Board, my tremendous gratitude for allowing me to assume editorial responsibilities for the next three volumes of the journal. They have expressed real trust in me, and I am nervous, excited, and grateful for this trust.

With this issue of the Journal I have found that much of the behind the scenes work of selecting and preparing manuscripts for publication is based on communication between the associate editors and authors. By talking through manuscript ideas, providing drafts to editors and colleagues, and simply talking through what is, has been, and will be written allows for a clarity that I did not know could so easily exist. In this first issue of Volume 8, three distinct articles are presented. First, Cindy Ann Dell, Richard D. Howard, and Kenneth W. Borland, Jr. provide a provocative look at the transition of Native American college students from tribally controlled colleges to Traditionally White Institutions. Readers may recall Professor Borland as a previous contributor to the Journal, and we collectively welcome him back and thank him for his continued support of creating an practitioner-oriented, academically-sound conversation about the meaning of orientation and transitional programs. Second, Carl H. Boening and Lara Anderson Miller explore writing apprehension among honors students at a case study institution. Although this manuscript does not overtly enter the debate about orientation, it does further the conversation with notations about implications for orientation professionals. This manuscript also introduces the idea that perhaps one or two articles of each volume can reflect broader student affairs issues to accompany the three or four orientation and transitional program specific articles. The third research-based article comes from the writing team headed by Beverly Dyer at the University of Alabama. Her study explores some of the unique dimensions that female students may encounter in an orientation program, a topic certainly in need of exploration.

This issue of the Journal is rounded out with four excellent book reviews, including one from former editor Bonita Jacobs and two professional contributions under the heading Campus Notes. As with previous editions of the Journal, I hope that the NODA

Michael T. Miller, Ph.D., is Associate Dean of the College of Education at San Jose State University, and Editor of The Journal of College Orientation and Transition. 
membership will continue to provide examples of best practice - and failures - for publication in the Campus Notes section of the Journal. Denise Rode provides strong leadership for this segment of the Journal, and I encourage you to contact her with your ideas.

In all of my conversations with current, previous, and potential authors, I have been asked repeatedly about what I think good topics for research would be for future studies and manuscripts. There are certainly a multitude of topical areas, such as financing orientation, retention of orientation professionals, service learning in orientation, training effectiveness, and so forth, but I am particularly curious about two areas. One is the psychological development and transition that students of all ages and developmental mindsets go through as they transition from different environments to the collegiate setting. Certainly we, as professionals, must have a sense of the impact of our programming on new students and the desired effects of program participation. I think we collectively need to explore the immediate and long-term influence of these activities. The second area ripe for research, and one consistently reported to me by associate editors, colleagues, and friends, is that of leadership within the profession. Do we really provide training for student leadership? Are we encouraging the types of conversations necessary for student growth so they are more than orientation team leaders? And, how do we, as professionals, encourage leadership among each other? My hope is that the membership and readership will at least consider some of these questions and report their best practice or ideas in future issues of the Journal.

In closing this inaugural editorial, let me again thank the associate editors, Bonita C. Jacobs, Jeanine Ward-Roof and the NODA Board of Directors for their support and faith in me to deliver this Journal. As an editorial board, our goal is to deliver to you cutting-edge research and best practice reports that help us as reflective-practitioners better prepare ourselves and future generations of students. 